\title{
SCREENING FOR SPINAL CURVATURES
}

\author{
Silviya Filkova ${ }^{1} \&$ Penka Mincheva-Bolgurova $^{2}$ \\ ${ }^{1}$ Medical College, Medical University - Varna, Bulgaria \\ ${ }^{2}$ National Sports Academy "Vasil Levski", Sofia, Bulgaria
}

\begin{abstract}
Spinal deformities have the highest incidence rate of all orthopedic problems in pediatrics. The earlier they are established, the more effective their correction will be.

Aim: To review the organization and carrying out screening programs for spinal curvatures with an emphasis on the need for carrying out screening programs.

Method: A computerized search was conducted in March 2019 in referenced databases like Medline, Pubmed and Ebscohost, as well as in literature published in Google Scholar, aimed at covering publications of studies conducted in a language other than English. Keywords used: children, postural disorders, screening, spinal curvatures.

Results: Two researchers have independently reviewed the abstracts and the full articles and have extracted data for analysis. There is a lack of standardization among screening tools. The variability of methods may compromise the comparison between the results of different studies.

Conclusion:

Opinions about the benefits of the use of screening are prevalent. Early diagnosis contributes to delaying progression, reducing the frequency of surgical intervention and reducing associated costs. The negative consequences of stopping the screening programs are not unanimous, but the missed benefits from the lack of screening are, in our opinion, a valid reason for their use.
\end{abstract}

Key words: children, postural disorders, screening, spinal curvatures.

\section{INTRODUCTION:}

In early 1984, the American Academy of Orthopedic Surgeons (AAOC) and the Scoliosis Research Society (SRS) recommended early screening for scoliosis with the understanding that Adolescent Idiopathic Scoliosis (AIS) is a condition that leads to a decrease in quality of life (Ha et al., 2018).

In 2007, the Pediatric Orthopaedic Society of North America (POSNA) and the American Academy of Pediatrics (AAP) also recommended early detection of scoliosis. The most recent position statement of the SRS, POSNA, AAOS and AAP on AIS screening, in 2015, calls for the screening of girls aged 10 to 12 and boys aged 13 to 14 (Hresko et al., 2016). The statement encourages the early detection of idiopathic scoliosis in adolescents in order to avoid surgical treatment. The main difference between the USPSTF statement for 2018 and the SRS, POSNA, AAOS, and AAP stems from the interpretation of the progression of untreated idiopathic scoliosis. Everyone is in agreement on the high accuracy of screening tests and the clinical efficacy of non-surgical treatment using general therapy and specific exercises for scoliosis. The 2015 position statement by SRS, POSNA, AAOS, and AAP does not include studies on the progression of untreated AIS, but instead suggests that the progression of the curve will lead to the need for surgical therapy (US Preventive Services Task Force, 2018). This has been proven in studies by Weinstein (2003) and in other studies (Weinstein et al.,2003; Dunn et al., 2018). In 2018, the USPSTF determined that the current evidence was insufficient to assess the balance of benefits and harms of screening for idiopathic scoliosis in adolescents (Ha et al., 2018).

The Australian National Health and Medical Research Council (NHMRC) recommends discontinuing screening for idiopathic scoliosis in schools because, despite the availability of relatively inexpensive screening tests for idiopathic scoliosis, there is no convincing evidence to suggest that they are useful and, furthermore, there is sufficient evidence available against screening and existing therapies for mild and moderate deformities (Plaszewski, 2012).

The UK National Screening Society does not recommend screening for scoliosis, given the uncertainty surrounding the effectiveness of screening and treatment (UK National Screening Committee, 
2017). However, the International Scientific Society on Scoliosis Orthopaedic and Rehabilitation Treatment (SOSORT) recommends screening for idiopathic scoliosis via school programs, which would be performed by clinicians specializing in the diagnosis of spinal deformities (Negrini et al., 2012, Grivas, 2007).

In Bulgaria, up until 1989, there was active prophylactic activity carried out for early detection and timely treatment of children with spinal curvatures. This activity was organized by the Ministry of Public Health and its bodies, and health facilities in the country, as well as by the Ministry of Public Education and its branches. At present, these good traditions are discontinued.

There is no doubt that existing screening tests are highly diagnostic and cost effective, while conservative treatment of scoliosis using orthopedic corsets and kinesitherapy is clinically effective after the have not been completely discontinued. Therefore, there is now a need to explore where in the world and in what groups is screening still taking place.

Aim: To review the organization and carrying out screening programs for spinal curvatures with an emphasis on the need for carrying out screening programs.

\section{METHODOLOGY}

A computerized search was conducted in March 2019 in referenced databases like Medline, Pubmed and Ebscohost, as well as in literature published in Google Scholar, aimed at covering publications of studies conducted in a language other than English. Keywords used: children, postural disorders, screening, spinal curvatures.

The following criteria have been defined for including original articles on:

1. The historical overview of the organization and management of screening programs in Bulgaria.

2. The historical overview of the organization and management of screening programs around the world.

\section{RESULTS}

Research and analysis of contemporary literary sources and scientific articles was carried out by experts from all over the world. A total of 195 full-text publications and 50 abstracts were identified. After all the articles were read and evaluated, forty-three articles were included in our study. The distribution of screening studies included in the study, grouped by the continent where the country is located, is as follows: one screening article each from South America, Africa and Australia, 11 articles from Asia, 5 articles from North America and 24 articles from Europe.

The historical review of the organization and management of screening programs found that screening for various diseases and scoliosis in particular in Europe dates back to the first decades of the 20th century. This is evidenced by a publication on the subject in "The Primary School" periodical of 1915 (Lambadarios, 1915). In this article, based on extensive personal clinical experience and analysis of similar studies, the author points out that idiopathic scoliosis is a "students' disease". In Europe and Asia, a variety of policies and laws apply to school screening for scoliosis. Today, scoliosis screening is not part of the national policies of the UK and Poland. (Burwell, 1988; Plaszewski, 2012).

From a retrospective study of Bulgarian literary sources, we found that performing prophylactic examinations of children of pre-school age and during early childhood in Bulgaria dates back to 1924, when Prof. Vatev and his associates opened the first child consultation in Sofia. The development of this idea is made possible after the creation of a wide and comprehensive pediatric network after 1944 (Bakalova, 1982). The prophylactic activity was directed towards spinal deformities in 1948, thanks to prof. N. Mancheva, who introduced the Soviet methodology for corrective gymnastics. For years, a number of studies have been carried out in kindergartens, schools and higher education institutions, with the aim of identifying deviations in physical development in order to begin healing and therapeutic activities in a timely manner. This practice was discontinued in 1989.

In 1915, Bancroft drew the public's attention to the importance of good posture during the school period. He founded the American Posture League to help monitor and maintain proper posture among the nation's youngest citizens (Linker, 2012). G. Dean MacEwen played an important role in the early development of school screening for scoliosis. In the 1960s, he developed and implemented programs in all the schools in the US state of Delaware (Bunnell, 2005, Grivas et al., 2007a). The model of 
screening for idiopathic scoliosis in schools spread around the world through publications by Kane, Lonstein, Winer, and Moe (Karachalios, 2000). Ohrt-Nissen et al., 2016, confirmed in their study that patients monitored by general practitioners in schools without a screening program had a larger curve than those from schools with a serious screening program (Ohrt-Nissen et al., 2016). In 1996, the respected and reputable USPSTF issued a statement, saying there was insufficient evidence regarding the effectiveness of scoliosis screening and therefore it could not support or oppose scoliosis screening (USPSTF, 1996).

Currently, the US lacks a federal law governing scoliosis screening in schools. As of 2003, screening has been legally introduced in 21 states, is recommended, but not obligatory, in 11 states, and in the rest it is conducted on a voluntary basis or is not recommended (Grivas et al.,2007b).

In some countries in Europe, like Italy, Spain, Netherlands, Bulgaria, Greece, Israel and Turkey, it was voluntary. On the island of Samos, Greece, X-ray screening for pulmonary diseases in all children has also identified cases of scoliosis (Karachalios, 1999).

In Sweden, in 1977, a conventional screening program was introduced, which included an annual compulsory screening of all schoolchildren aged 7 to 16 (Montgomery, 1993). The examination was performed by a specially trained nurse, using Adam's test. Sweden is the only Scandinavian country with an active school screening for scoliosis (Adobor et al.,2011). At least 200,000 children are screened annually by school nurses and doctors. The purpose is to diagnose children with moderate scoliosis, where the progression can be controlled with orthopedic corsets.

In the Irish screening program, children who have not been diagnosed with scoliosis are to be screened again after 1 to 4 years. Cases where the curve has a Cobb angle of $40^{\circ}$ or greater are considered positive (Goldberg et al.1995). In Dublin, Goldberg et al., (1995) concluded that the main objective of the program has not been achieved, although the implementation of school scoliosis screening since 1979 has contributed significantly to awareness for AIS (Goldberg et al.1995).

In the Netherlands, in 2008, Bunge et al., (2008) conducted control studies to evaluate the effectiveness of school screening for scoliosis (Bunge,
2008). Their results show no evidence that the use of Adam's test in school screening for scoliosis reduces the need for surgery. Based on that, they conclude that it is appropriate to discontinue screening. In Norway, school screening for scoliosis was performed in the 1970s and 1980s. In 1994, the screening was discontinued, based on USPSTF recommendations (Adobor et al., 2011).

In Denmark, children undergo screening for scoliosis by school doctors and nurses using Adam's test. After the introduction of Moiré topography, despite the numerous subjectively positive results for scoliosis, twice as many cases of scoliosis were detected as with conventional clinical screening (Laulund et al., 1982, Adobor et al., 2011).

Following a study and analysis of the need for school screening for scoliosis, the Polish Agency for Health Technology Assessment did not recommend the implementation of a regional program for the prevention of postural deformities in children (Plaszewski, 2012).

In northwestern and central Greece. In 1997, Soucacos et al.,used Adam's test in their screening program. They concluded that scoliosis screening appears to be an effective method for the early detection and non-surgical treatment of scoliosis, generating invaluable data on the spread and natural history of spinal deformities (Soucacos, 1997).

In Bulgaria, after 1989, within various research projects, related to screening and implementation of kinesitherapy programs for postural deformities and scoliosis are carried out irregularly and only in some cities in the country, such as Sofia, Varna, Ruse, Veliko Tarnovo, Burgas, Stara Zagora, Blagoevgrad (Dimitrova et al., 2013; Zaharieva et al., 2013; Manikatov et al., 2011; Popova-Dobreva et al., 2010; Stoyanova-Borisova, 2013; Tasheva et al., 2013 Mitova, 2014; Popova, 2015; Chongov et al., 2017; Paskaleva et al., 2014).

In Japan, the screening program for scoliosis in schools is mandated by law. However, the actual program depends on the local education committees as they are responsible for its implementation. School screening programs date back to 1979 and are implemented by the Chiba University Medical School. By 1986, 1,246,798 students were covered. The programs are implemented using the Moiré topographic method and radiography, if necessary (Takemitsu, 1978). The "Adolescent Scoliosis Screening in Nara City Schools" screening program 
was conducted between 1990 and 2012. 195,149 children aged 11 to 14 were covered (Takemitsu et al., 1978). Currently, some Japanese doctors are trying to develop new instruments for test batteries for school screening, using information technology (IT).

The other Southeast Asian countries are not running national screening programs, although special screening is carried out in schools in local communities in Malaysia, Indonesia and Vietnam.

In Singapore, routine screening examinations for spinal curvatures in children in schools are part of the national program for conducting on-site medical examinations in schools from 1982 to present day (Yong, 2009).

Chinese researchers have conducted a surveys for scoliosis as early as 1986. The Peking Union Medical College Hospital (PUMCH) screened 21,759 children aged 8 to 14 in Beijing (Wang et al., 1996). As of 2012, only three provinces and one municipality in China are conducting school screening programs for scoliosis (Karachalios, 1999). School screening programs for scoliosis are not currently part of China's health care system. There are no national screening programs in China: the only established school screening program for scoliosis is in Hong Kong. School screening for scoliosis in Hong Kong began in November 1995 as a voluntary program, part of the annual national plan for health assessment, managed by the Ministry of Health.

In Africa and South America there are no recent dissemination studies based on school study programs published at least in English. According to a study by Jenyo et al.,2005 conducted in Nigeria, 410 children aged 9 to 14 were examined and a $1.2 \%$ incidence of scoliosis was established (Jenyo et al.,2005).

In Brazil in 2010, Nery et al.,screened 1340 twelveyear-old children and found a $1.4 \%$ incidence rate of scoliosis (Nery et al., 2010).

In Australia, scoliosis screening at school was introduced in the early 1990s, but the factors affecting the organization and costs have led to the suspension of most screening programs in public schools. A national self-detection program for scoliosis was organized, which consists of the dissemination of an information brochure aimed at the target age group of 11 to 13 years, outlining the external signs of scoliosis. If, after reading the brochure, parents suspect their child has a spinal curvature, a consultation with the family doctor is recommended. An educational program for scoliosis has also been introduced for GPs (The National Self-Detection Program for Scoliosis).

\section{DISCUSSION}

Over the past 60 years, screening programs of various design have been developed and implemented around the world (Fong et al., 2010). The topic of school screening is subject to constant debate. It is often supported by clinicians, based on the fact that early detection makes conservative treatment more effective and thus minimizes the risk of invasive surgery.

Today, there are published research findings from all the continents, although there are variations in the research data which may be due to the variations in study design, inclusion criteria, screening tests used, screening frequency and duration of follow-up.

For example, there is no national requirement or standard for scoliosis screening in the United States. Such policies exist at the local, state or school level. There is also a great deal of variety in scoliosis screening policies worldwide. Screening programs differ in terms of environment, people doing the screening and methods used.

In some European countries, it is performed voluntary.

Australia, as a result of the implementation of the „National Scoliosis Self-Detection Program”, modern studies in this area are significantly limited (Grivas et al.,2006).

The topic of the pros and cons of implementing postural deformity screening programs is still being discussed. Literature reviews that support the recommendation for school screening (Fong et al.,2010, Fong et al.,2015), as well as opinions against screening (Negrini et al., 2005, National Health and Medical Research Council, 2002) are based on different studies based, which are based on different evidence, and that makes them unconvincing.

\section{CONCLUSION}

Although there is no direct evidence of the bene- 
fit or harm of AIS screening, it is still performed around the world, though not on a large scale. There is consensus that early diagnosis contributes to delaying progression, reducing the frequency of surgical intervention and reducing associated costs. Opinions that support the benefits of the use of screening are therefore prevalent. The negative consequences of stopping the screening programs are not unanimous, but the missed benefits from the lack of screening are, in our opinion, a valid reason for their use.

\section{REFERENCES}

Adobor, RD., Rimeslatten, S., Steen, H., Brox, JI. (2011). Scoliosis screening and point prevalence of adolescent idiopathic scoliosis in 4000 Norwegian children aged 12 years. Scoliosis 6: 23.

Bakalova, L. (1982). A workguide for prophylactic children facilities. Sofia: Medicine and Physical Culture, pp. 287.

Bunge, EM., Juttmann, RE., van Biezen, FC., Creemers, H., Hazebroek-Kampschreur, AAJM., Luttmer, BCF, Wiegersma, PA., de Koning, HJ. (2008). Estimating the effectiveness of screening for scoliosis: a case-control study. Pediatrics 121(9): 9-14.

Bunnell, WP. (2005). Selective screening for scoliosis. Clin Orthop Relat Res. 40-45.

Burwell, G. (1988). The British decision and subsequent events. Spine. 1988, 13: 1192-1194.

Chongov, B., Alexiev, V., Georgiev, H., Kalinov, K., Dimitrova, E. (2017). Correlation between scoliosis deformity type and trunk symmetry before and after schroth physiotherapeutic exercises. Comptes rendus de l'Académie bulgare des Sciences. 70, (10), 1455-1462.

Dimitrova, E., Chavdarova, M., Popova - Dobreva, D., Sazdova, L., Markovska, G., Mincheva, P., Popova N. (2013). Analysis of the results of screening for postural disorders and flat feet in children in preparatory pre-school classes. Sofia: Compendium of NSA reports, pp. 24-32.

Dunn, J., Henrikson, NB., Morrison, CC., et al. (2018). Screening for Adolescent Idiopathic Scoliosis: A Systematic Evidence Review for the U.S. Preventive Services Task Force. Rockville, MD: Agency for Healthcare Research and Quality (US).

Fong, DY., Cheung, KM., Wong, YW., Wan, YY., Lee, CF., Lam, TP., et al. (2015). A population-based cohort study of 394,401 children followed for 10 years exhibits sustained effectiveness of scoliosis screening. Spine J. 15(5):825-833.

Fong, DY., Lee, CF., Cheung, KM., Cheng, JC., Ng, BK., Lam, TP., Mak, KH., Yip, PS., Luk, KD. (2010). A me- ta-analysis of the clinical effectiveness of school scoliosis screening. Spine 35:1061-1071.

Goldberg, CJ., Dowling, FE., Fogarty, EE., Moore, DP. (1995). School scoliosis screening and the United States preventive services task force: an examination of longterm results. Spine. 20(12): 1368-1374.

Grivas, T.B., Wade, M.H., Negrini, S., O'Brien, J.P., Maruyama, T., Hawes, M.C., Rigo, M., Weiss, H.R., Kotwicki, T., Vasiliadis, E.S., Sulam, L.N. and Neuhous, T. (2007a) SOSORT consensus paper: school screening for scoliosis. Where are we today? Scoliosis 2:17

Grivas, TB., Vasiliadis, E., Maziotou, C., Beltsios, M., Psarakis, S., Segos, D. (2007b). Cost analysis of a school-screening program. 4th International Conference on Conservative Management of Spinal Deformities, Boston, USA.

Grivas, TB., Vasiliadis, E., Mouzakis, V., Mihas, C., Koufopoulos, G. (2006). Association between adolescent idiopathic scoliosis prevalence and age at menarche in different geographic latitudes. Scoliosis. 2006; 1:9. Published May 23.

Ha, AS., Beauchamp, EC. (2018). Editorial on "Screening for adolescent idiopathic scoliosis: US preventive services task force recommendation statement". J Spine Surg. 4(4):812-816.

Hresko, MT., Talwakar, VR., Schwend, RM. (2017). SRS/ POSNA/AAOS/AAP position statement: screening for the early detection for idiopathic scoliosis in adolescents. https://www.srs.org/about-srs/news-and-announcements/position-statement---screening-for-the-early-detection-for-idiopathic-scoliosis-in-adolescents. 2015. Accessed November

Hresko, MT., Talwalkar, V., Schwend, R. (2016). Early detection of idiopathic scoliosis in adolescents. J Bone Joint Surg Am 98:e67. 10.2106/JBJS.16.00224

Jenyo, MS., Asekun-Olarinmoye, EO. (2005). Prevalence of scoliosis in secondary school children in Osogbo, Osun State, Nigeria. Afr J Med Med Sci. Dec; 34(4):361-4.

Karachalios, T., Sofianos, J., Roidis, N., et al. (1999). Tenyear follow-up evaluation of a school screening program for scoliosis: is the forward-bending test an accurate diagnostic criterion for the screening of scoliosis? Spine (Phila Pa 1976). 24(22):2318-24 7p

Lambadarios, EN. (1915). Scoliosis. Diseases of school. Aristidou str 1, Athens, Greece: Thanos Tzavelas Publisher.

Laulund, T., Søjbjerg, JO., Hørlyck, E. (1982). Moiré topography in school screening for structural scoliosis. Acta Orthop Scand 53: 765-768.

Manikatov, D., Nikolova, E. (2011). Corrective gymnas- 
tics in physical education and sports classes, in cases of early spinal changes, a factor for functional improvement in children aged 7-9. Union of Scientists in Bulgaria, Blagoevgrad Branch, yearbook vol. V, pp. 157-165 Mitova, S. (2014). Screening studies of postural deformities of the musculoskeletal system in adolescents. Scientific papers of the University of Ruse - Volume 53, Series 8.1, pp. 99-102.

Montgomery, F., Willner, S. (1993). Screening for idiopathic scoliosis: comparison of 90 cases shows less surgery by early diagnosis. Arch Orthop Traumat Surg, 64(4): 456-458.

National Health and Medical Research Council (2002). Child health screening and surveillance: a critical review of the evidence. Centre for Community Child Health, Royal Children's Hospital Melbourne.

Negrini, S., Aulisa, AG., Aulisa, L., et al. (2012). 2011 SOSORT guidelines: orthopaedic and rehabilitation treatment of idiopathic scoliosis during growth. Scoliosis. 7(1):3.

Negrini, S., Aulisa, L., Ferraro, C., Fraschini, P., Masiero, S., Simonazzi, P., Tedeschi, C., Venturin, A. (2005). Italian guidelines on rehabilitation treatment of adolescents with scoliosis or other spinal deformities. Eura Medicophys 41:183-201.

Nery, Lenice Sberse, Halpern, Ricardo, Nery, Paulo César, Nehme, Karin Passos, \& Tetelbom Stein, Aírton (2010). Prevalence of scoliosis among school students in a town in southern Brazil. Sao Paulo Medical Journal, 128(2), 69-73.

Ohrt-Nissen, S., Hallager, DW., Henriksen, JL., Gehrchen, M., Dahl, B. (2016). Curve Magnitude in Patients Referred for Evaluation of Adolescent Idiopathic Scoliosis: Five Years' Experience From a System Without School Screening. Spine Deform. 4(2):120-124.

Paskaleva, R., Milcheva, H., Mollova, K., Petrova, M., Uzunova, A. (2014). New approach in the practical training of students for prevention of spinal deformities in kindergartens - Trakya University, Stara Zagora in Turkey, Odrin, 2014 - 9th International Balkan Education Science Congres. 16-18 October p. 959-964.

Plaszewski, M., Nowobilski, R., Kowalski, P., Cieslinski, M. (2012). Screening for scoliosis: different countries' perspectives and evidence-based health care. Int J Rehabil Res 35(1): 13-19.

Popova, N. (2015). Functional study methodology for postural disorders in middle school age. Sports and Science, ISSN 1310-3393, NSA Press, issue 3, pp. 132-139.

Popova-Dobreva, D., Markovska, G. Gencheva, N. Genchev, K. (2010). Distribution of flat feet among elementary school students. Sofia: Sports and Science, special issue, Part II. 2010, pp. 393-397.
Soucacos, PN., Soucacos, PK., Zacharis, KC., Beris, AE., Xenakis, TA. (1997). School-screening for scoliosis: a prospective epidemiological study in northwestern and central Greece. J Bone Joint Surg Am 79: 1498-1503.

Stoyanova-Borisova, Z. (2013). Integrated approaches for prevention and rehabilitation for children with improper posture and spinal curvature. In: Scientific Papers of the University of Ruse, Volume 52, Series 8.1, pp. $116-120$

Takemitsu, Y., Harada, Y., Ando, M. (1978). Incidence of scoliosis in Japan by mass screening examination of school children. Orthop Trans. 2:278.

Tasheva, R., Kolev, K. (2013). Indications of Adam's and Matthias' tests in children with deviations in the frontal plane. Sofia: Compenidum of reports, NSA, pp. 95-100.

The National Self-Detection Program for Scoliosis http://www.scoliosis-australia.org/pdfs/self_detection _ program_download06.pdf

UK National Screening Committee. (2017). The UK NSC recommendation on adolescent idiopathic scoliosis screening. https://legacyscreening.phe.org.uk/scoliosis. 2016. Accessed November 14.

US Preventive Services Task Force. (2018). Screening for Adolescent Idiopathic Scoliosis: US Preventive Services Task Force Recommendation Statement. JAMA. 319(2):165-172.

USPSTF (1996). Guide to Clinical Preventive Services. 2nd ed, Office of Disease Prevention and Health Promotion, Washington, DC.

Wang, YP., Ye, QB., Wu, B. (1996). Result on the screening of scoliosis among school students in Beijing area. Chin J Epidemiol.;17:160-2.

Weinstein, SL., Dolan, LA., Spratt, KF., et al. (2003). Health and function of patients with untreated idiopathic scoliosis: a 50-year natural history study. JAMA 289:559-67. 10.1001/jama.289.5.559

Yong, F., Wong, HK., Chow, KY. (2009). Prevalence of adolescent idiopathic scoliosis among female school children in Singapore. Ann Acad Med Singapore. 38(12):1056-1063.

Zaharieva, D., Angelcheva, M. (2013). Ergonomics of the school environment for promoting good posture in seven- to eight-year-olds. In: Compendium of NSA reports, pp. 41-50.

Correspondence to: Silviya Filkova, PhD, Rehabilitator Training Sector,

Medical College, Medical University of Varna, 84 Tzar Osvoboditel Str., 9000, Varna, Bulgaria, E-mail: s.filkova@abv.bg 